\title{
SAR150640, a selective $\beta_{3}$-adrenoceptor agonist, prevents human myometrial remodelling and activation of matrix metalloproteinase in an in vitro model of chorioamnionitis
}

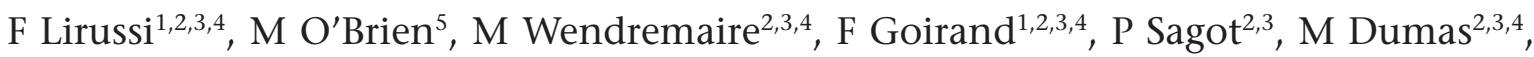 \\ $\mathrm{JJ}_{\text {Morrison }}^{5}$ and M Bardou ${ }^{1,2,3,4}$ \\ ${ }^{1}$ Centre d'Investigations Cliniques plurithématique 803 (INSERM CIC-P 803), Dijon, France, ${ }^{2}$ CHU de Dijon, Dijon, France, \\ ${ }^{3}$ Laboratoire de Physiologie et Pharmacologie Cardiovasculaires Expérimentales (LPPCE), IFR Santé-STIC, Dijon, France, \\ ${ }^{4}$ Université de Bourgogne, Dijon, France and ${ }^{5}$ Clinical Science Institute, National University of Ireland Galway, University \\ College Hospital Galway, Galway, Ireland
}

Background and purpose: The uterine pathophysiology underlying inflammatory conditions such as chorioamnionitis remains largely unclear. As we have shown that $\beta_{3}$-adrenoceptors act as regulators of myometrial inflammation, we wanted to investigate the potential role of $\beta_{3}$-adrenoceptors in preventing uterine remodelling induced by inflammation.

Experimental approach: The consequences of human chorioamnionitis on myometrial remodelling were characterized by Sirius Red staining and metalloproteinase (MMP) expression, and compared with the effects of incubating human myometrial samples with Escherichia coli lipopolysaccharide (LPS) in vitro. We also assessed the effect of SAR150640, a selective $\beta_{3}$-adrenoceptor agonist, on the production and activity of MMPs.

Key results: Chorioamnionitis was associated with a $46 \%$ decrease in total collagen, as well as over-expression of MMP2 (+61\%) and MMP9 (+84\%); both effects were reproduced by incubation with LPS (10 $\left.\mu \mathrm{g} \cdot \mathrm{mL}^{-1}, 48 \mathrm{~h}\right)$. LPS-induced overexpression of MMP2 and MMP9 in normal human myometrium was paralleled by an overactivity of the proteins. Both over-expression and overactivity were prevented by the $\beta_{3}$-adrenoceptor agonist SAR150640 in a concentration-dependent manner. SAR150640, by itself, did not exhibit any effect on MMP production in control tissues.

Conclusions and implications: This study shows that inflammation was associated with an intense remodelling of human myometrium, a process likely to be explained by MMP activation. Our study emphasizes the potential therapeutic relevance of $\beta_{3}$-adrenoceptor agonists to the treatment of preterm labour and other uterine inflammatory conditions.

British Journal of Pharmacology (2010) 159, 1354-1366; doi:10.1111/j.1476-5381.2009.00616.x; published online 5 February 2010

Keywords: $\beta_{3}$-adrenoceptor; pregnancy; human myometrium; chorioamnionitis; lipopolysaccharide; matrix metalloproteinase (MMP); inflammation; bacterial infection

Abbreviations: CA, chorioamnionitis; LPS, lipopolysaccharide; MMP, matrix metalloproteinase

\section{Introduction}

The incidence of premature birth has increased over the past 15 years (Goldenberg et al., 2008), and spontaneous preterm delivery remains relatively high (5-12\%) in developed countries despite preventative measures (Goldenberg and Rouse, 1998; Ananth et al., 2001; Martin et al., 2006). Spontaneous

Correspondence: Marc Bardou, INSERM CIC-P 803, CHU du Bocage, 1, bd Jeanne d'Arc, 21079 Dijon, France. E-mail: marc.bardou@u-bourgogne.fr Received 29 May 2009; revised 11 September 2009; accepted 9 November 2009 preterm labour, whether explained or unexplained, is one of the leading causes of preterm birth, accounting for at least one-third of infant deaths and for $40 \%$ of disability at 5 years of age (Larroque et al., 2008). Many cases of spontaneous preterm labour are unexplained, but a significant proportion is linked to genital tract infection or chorioamnionitis (Edwards, 2005).

Several stimulatory and inhibitory pathways regulate the balance of uterine quiescence and contractile activity during pregnancy, but the specific changes that govern the switch between these opposing functional states are still poorly understood (Smith, 2007). Inflammation has been closely 
implicated in the mechanisms responsible for preterm and term parturition, and in the development of fetal injury (Romero et al., 2007; Christiaens et al., 2008). Recent reports suggest that some cytokines, for example a combination of low interleukin (IL)-18 and high IL-12, might be associated with an increased risk for delivery before 34 weeks (Ekelund et al., 2008).

We have recently demonstrated that chorioamnionitis is associated with apoptosis of myometrial smooth muscle cells (Lirussi et al., 2008). In reproductive tissues, cellular turn-over leads to apoptosis and is frequently associated with remodelling of the extracellular matrix neighbouring the apoptotic cells (Fata et al., 2000). Furthermore, different studies have suggested that remodelling of extracellular matrix is directly implicated in the control of parturition and labour (Roh et al., 2000; O'Brien et al., 2007). It is evident that explicit reorganization of extracellular matrix at the end of pregnancy is critical for the uterus to achieve the powerful synchronous contractions during labour, and to enable the post-partum uterus to return to its pre-pregnancy state (Monga and Sanborn, 1995; Manase et al., 2006). This process is associated with a breakdown of collagen that accounts for most of the reduction in uterine size (Shimizu and Maekawa, 1983). Collagen I and III comprise the two major components of myometrial extracellular matrix (Schwalm and Dubrauszky, 1966). The digestion of these components is under control of matrix metalloproteinases (MMPs), collectively called matrixins. MMP9 and MMP2, also known as gelatinase A and B, are often studied because they are able to degrade a variety of extracellular matrix components including collagens I, II, III, IV, V and XI, and elastin, proteoglycan and gelatin (Visse and Nagase, 2003).

While a significant increase in the expression of different MMPs (MMP1, 2, 3 and 9) occurs with the onset of term and preterm parturition in placenta, fetal membranes and amniotic fluid (Weiss et al., 2007), little is known about the production and regulation of MMP in human myometrium. Nevertheless, several studies have shown that MMP9 expression increases in human myometrium during labour (Roh et al., 2000; Vadillo-Ortega and Estrada-Gutierrez, 2005; Weiss et al., 2007). More recently, O'Brien et al. (2007) have shown that MMP3 expression is also increased with onset of labour, thus leading to the degradation of uterine $\alpha 5$ integrin (ITGA5), a receptor that mediates cell attachment to the extracellular matrix. In support of this work, a recent paper has suggested that MMP-1 and MMP-3 are over-expressed in chorioamnionitis-complicated decidua versus control preterm and term decidual specimens (Oner et al., 2008).

The pharmacological management of preterm labour is based on the use of various drugs aimed to inhibit myometrial contractions, known as tocolytic agents. We have previously shown that the $\beta_{3}$-adrenoceptor (nomenclature follows Alexander etal., 2008) is the predominant $\beta$-adrenoceptor in human myometrium (Bardou et al., 2000; Dennedy et al., 2002; Rouget et al., 2005), with an inhibitory action on spontaneous contractions. In contrast with the $\beta_{2}$-adrenoceptor, the $\beta_{3}$-adrenoceptor has the interesting property of being resistant to long-term agonist-induced desensitization (Rouget et al., 2004). Furthermore, we have recently reported that $\beta_{3}$-adrenoceptor stimulation was able to oppose both human myometrial apoptosis and inflammation in an experimental model of chorioamnionitis (Lirussi et al., 2008). Because of these findings suggesting a potential application of $\beta 3$-adrenoceptor stimulation in the pharmacological management of preterm labour, the aims of this study were as follows: (i) to assess the consequences of chorioamnionitis on extracellular matrix remodelling in human myometrium; (ii) to test the capacity of our in vitro model of Escherichia coli lipopolysaccharide (LPS)-induced chorioamnionitis to reproduce this remodelling; and (iii) to assess the ability of the newly described selective $\beta_{3}$-adrenoceptor agonist, SAR150640 (Croci et al., 2007), to prevent the extracellular consequences of LPS-induced chorioamnionitis.

We found that SAR150640 was able to prevent the increase in MMP activity and production observed after LPS stimulation or in cases of chorioamnionitis. This study, in addition to our earlier work, strengthens the potential role of $\beta_{3}$-adrenoceptors in the pharmacological management of preterm labour.

\section{Methods}

\section{Materials}

LPS (E. coli 055:B5, ref: L2880) and propranolol were purchased from Sigma-Aldrich (St Louis, MO, USA), and dissolved in distilled water. SAR150640 was a gift from Sanofi-Midy Research Centre, Exploratory Research Department, SanofiAventis S.p.A (Milan, Italy). It was dissolved in a mixture of $30 \%$ absolute ethanol, 2\% dimethylsulphoxide (DMSO) and distilled water for the $1 \mathrm{mM}$ solution and thereafter diluted in distilled water. The final maximal bath concentration was $0.3 \%$ for ethanol and $0.02 \%$ for DMSO.

\section{Biological samples}

This study was authorized by the French authorities (registration number 2007-A01056-47), approved by the 'Comité de Protection des Personnes' (CPP-Est 1, Dijon, France) and written informed consent was obtained from all donors.

Myometrial biopsies were obtained from women during pregnancy in two different clinical situations as outlined: (i) three women undergoing elective caesarean section with established chorioamnionitis (one with rupture of membranes, two with positive placental cultures involving $E$. coli in one case and Ureaplasma urealyticum in the other case and one with the diagnosis confirmed only by histological assessment of the placenta); (ii) 20 women undergoing elective caesarean section for other reasons (cephalo-pelvic disproportion) in the absence of chorioamnionitis. All caesarean sections were performed prior to the onset of labour at a gestation period between 38 and 40 weeks of pregnancy. Clinical chorioamnionitis was defined classically (Redline et al., 2005) as the presence of uterine tenderness and/or purulent or foul-smelling amniotic fluid with any two of the following: antepartum temperature of $37.8^{\circ} \mathrm{C}$ or more, maternal tachycardia (more than 120 beats. $\mathrm{min}^{-1}$ ), maternal leukocytosis more than 18000 cells $\cdot \mathrm{mm}^{-3}$ or fetal tachycardia (more than 160 beats. $\mathrm{min}^{-1}$ ), and was confirmed, in all cases 
included in the present study, by either a positive culture of the placenta or a histological assessment of the placenta by a single pathologist using validated criteria (Redline et al., 2003). Therefore, in the remainder of this paper, chorioamnionitis refers to confirmed chorioamnionitis. Pregnancies were considered uncomplicated when there was no evidence of clinical chorioamnionitis (i.e. infection), and, in this setting, no bacteriological or histological assessment of placenta was performed. We appreciate that normal labour is closely linked with a uterine/fetal membrane inflammatory response, but this is quite a different phenomenon to chorioamnionitis.

Myometrial strips were excised from an immediately subserosal site, and at an anti-placental site, as previously described (Leroy et al., 1989; Lirussi et al., 2008).

Tissue samples obtained from women with confirmed chorioamnionitis were either used fresh to perform Western blot experiments, or embedded in paraffin for histological assessment and Sirius Red staining, as described below.

Myometrial biopsies obtained from uncomplicated pregnancies were used to develop the LPS experimental model mimicking the effects of chorioamnionitis, a model that was recently described to reproduce myometrial changes induced by chorioamnionitis (Leroy et al., 1989; Lirussi et al., 2008).

\section{Stimulation of myometrial biopsies by E. coli LPS}

Myometrial biopsies obtained from women with uncomplicated pregnancies were immediately transferred in sterile Dulbecco's modified Eagle's medium (DMEM), and washed twice with sterile phosphate-buffered saline (PBS). Biopsies were cut into small strips, each being placed in a 24-well plate containing $2 \mathrm{~mL}$ of culture medium DMEM, without the use of antibiotics. Strips were then incubated at $37^{\circ} \mathrm{C}$ with $5 \% \mathrm{CO}_{2}$ for $48 \mathrm{~h}$ in order to allow cytokine levels to return to basal values (Fortunato et al., 1994).

In order to reproduce with LPS (E. coli 055:B5), the findings on myometrial samples obtained from women with chorioamnionitis, myometrial strips were incubated with LPS $\left(10 \mu \mathrm{g} \cdot \mathrm{mL}^{-1}\right)$ at different times $(6,12,24$ and $48 \mathrm{~h})$, as previously reported (Leroy et al., 1989; Lirussi et al., 2008).

In a second set of experiments aimed to assess the ability of $\beta_{3}$-adrenoceptor stimulation to oppose LPS-induced MMP expression/activation, myometrial strips were incubated with LPS $10 \mu \mathrm{g} \cdot \mathrm{mL}^{-1}$ for $48 \mathrm{~h}$ without or with SAR150640 $(0.1,1$ and $10 \mu \mathrm{M})$, a selective $\beta 3$-adrenoceptor agonist (Croci et al., 2007) added immediately before starting the incubation with LPS. Time-matched control experiments were performed with the solvent of SAR150640 (i.e. distilled water containing $0.3 \%$ ethanol and $0.02 \%$ DMSO as final bath concentration).

In a third set of experiments, in order to assess the specificity of the effect observed with the SAR150640 on MMP9 expression and activation, we used propranolol, a nonselective $\beta$-adrenoceptor antagonist $(0.1 \mu \mathrm{M}$ in order to block selectively $\beta_{1}$-adrenoceptors and $\beta_{2}$-adrenoceptors, and $10 \mu \mathrm{M}$ to block all the $\beta$-adrenoceptors (Roberts et al., 1995; Hoffmann et al., 2004). Time-matched control experiments were performed with the solvent of propranolol (i.e. distilled water).
At the end of the stimulation period, the supernatants of samples and tissues were quickly frozen in liquid nitrogen and stored at $-80^{\circ} \mathrm{C}$.

\section{Zymography analysis}

The proteolytic activity of pro-MMP9 and pro-MMP2 secreted into the culture medium was assessed by zymography on a $10 \%$ sodium dodecyl sulphate (SDS) gel incorporating $1 \mathrm{mg} \cdot \mathrm{mL}^{-1}$ gelatin. Culture medium corresponding to $0.5 \mathrm{mg}$ of tissue was loaded and subjected to electrophoresis. The gels were then washed twice in $2.5 \%$ Triton $\mathrm{X}-100$ for $30 \mathrm{~min}$ and incubated for $18 \mathrm{~h}$ at $37^{\circ} \mathrm{C}$ in $50 \mathrm{mM}$ Tris- $\mathrm{HCl}, 5 \mathrm{mM} \mathrm{CaCl}_{2}$, $200 \mathrm{mM} \mathrm{NaCl}$ and $0.02 \%$ sodium azide (pH 7.6). The gels were stained with Coomassie blue in 30\% ethanol and 10\% acetic acid for $1 \mathrm{~h}$ at room temperature, and then destained in $25 \%$ ethanol and $10 \%$ acetic acid. Clear bands on a blue background indicate the presence of gelatin-degrading proteinases. The gelatinolytic activity of pro-MMP9 $(92 \mathrm{kDa})$ was estimated by scanning the wet gels with a densitometer and analyzing the data with the NIH Image 1.60 software package (National Institutes of Health, Bethesda, MD, USA). Results were expressed in arbitrary densitometric units.

\section{Real-time quantitative RT-PCR}

Total RNA was prepared from three myometrial tissues obtained from three different women, using Trizol solution (Life Technologies, Groningen, The Netherlands) according to the manufacturer's instructions. The integrity of RNA was verified by edithidium bromide staining of agarose gel analysis and by an optical density absorption ratio OD260 nm/ OD280 $\mathrm{nm} \geq 1.8$. One microgram of total RNA was reverse transcribed with Super Script II RNAase H-reverse transcriptase (Invitrogen Life Technologies, Groningen, the Netherlands) using oligo (dT) according to the manufacturer's instruction. Real-time quantitative PCR analyses were performed using $25 \mathrm{ng}$ of reverse transcribed total RNA with $400 \mathrm{nM}$ of both sense and anti-sense primers in a final volume of $25 \mu \mathrm{L}$ using the SYBR Green PCR jumpstart reagent (Sigma) in an iCycler iQ real-time detection system instrument (BioRad, Marnes-la-Coquette, France). PCR products were also analysed on edithium bromide stained agarose gel to ensure that a single amplicon of the expected size was indeed obtained.

Each reaction was performed in triplicate, and $\beta$-actin was used in each experiment to control for variability in the quantities of cDNA. Relative quantification for any given gene, expressed as fold variation over control, was calculated after determination of the difference between cycle threshold $(C t)$ value of the given gene according to the manufacturer's protocol using the formula $2-\Delta(\Delta C t \mathrm{~A}-\Delta C t \mathrm{~B})$, in which $\Delta C t \mathrm{~A}$ is $\Delta C t$ of the gene of interest, and $\Delta C t \mathrm{~B}$ is $\Delta C t$ of glyceraldehyde-3-phosphate dehydrogenase (GAPDH). $\Delta C t=$ $C t$ of the experimental group - Ct of the control group. PCR was performed using specific primers (see Table 1)

\section{Sirius Red analysis}

The myometrial strips were fixed for $1 \mathrm{~h}$ with $4 \%$ paraformaldehyde, embedded in paraffin and cut into $5 \mu \mathrm{m}$ thick 
Table 1 Sequences of primers for RT-PCR

\begin{tabular}{lll}
\hline Gene name & \multicolumn{1}{c}{ Forward primer } \\
\hline MMP1 & Geverse primer \\
MMP2 & TGGAGATCATCGGGACAACTC & GGGCCTGGTTGAAAAGCAT \\
MMP3 & TGGCATTCAGTCCCTCTATGG & GGCTTGCGAGGGAAGAAGTT \\
MMP9 & GTGCTGGGCTGCTGCTTTGCTG & AGGACAAAGCAGGATCACAGTT \\
GAPDH & TGCACCACCAACTGCTTAGC & GTCGCCCTCAAAGGTTGGAAT \\
\hline
\end{tabular}

sections. The sections were then incubated for $10 \mathrm{~min}$ with thiosemicarbazide $(0.5 \%)$ and stained in Sirius Red F3B (0.1\%) in saturated picric acid for $1 \mathrm{~h}$, and subsequently washed with acetic acid (0.5\%). Experiments were performed in triplicate in myometrial samples obtained from three different women with chorioamnionitis (CA group) and in six myometrial samples obtained from women with uncomplicated pregnancies. Three of them were stimulated with LPS, in the absence or in the presence of the $\beta_{3}$-adrenoceptor agonist at $0.1,1$ and $10 \mu \mathrm{M}$, and the three others were used as controls. The images were captured by digital imaging system, and analysed with Histolab software (Microvision Instruments, Evry, France). The slides were examined through polarized light, and constant area of integration was recorded for each section and averaged for each group. Picrosirius Red stains collagen red on a pale yellow background in bright field microscope, whereas, under a polarization microscope, collagen appears bright orange-red and/or bright green. According to Junqueira et al. (1979), the birefringence is highly specific for collagen. This approach has been used several times since then, and validated in different models (Zhang et al., 2006; Borges et al., 2007). The results were expressed in percentage of fluorescence $\mathrm{mm}^{-2}$.

\section{Western blotting analysis}

Snap-frozen myometrial tissues were homogenized with UltraTurrax in homogenization buffer [10 mM Tris-HCl (pH 7.4), $1 \mathrm{mM}$ EDTA, $40 \mathrm{mg} \cdot \mathrm{mL}^{-1}$ leupeptin, $2 \mathrm{mM}$ Pefabloc]. After an initial centrifugation at $5000 \times \mathrm{g}$ for $15 \mathrm{~min}$ at $4^{\circ} \mathrm{C}$, total protein supernatant content was determined by the Bradford method with BSA as standard. Samples ( $40 \mu \mathrm{g}$ of protein by lane) were dissolved (vol/vol) in $2 \times$ Laemmli buffer and boiled for $5 \mathrm{~min}$ before electrophoresis on a 10\% SDS-PAGE. Proteins were transferred to a nitrocellulose membrane (Hybond-P, Amersham Biosciences, Pantin, France). In order to block non-specific antibody binding, membranes were incubated for $1 \mathrm{~h}$ in $10 \%$ non-fat dried milk powder in Tris-buffered saline/ Tween 20 (TBST) (10 mM Tris, $150 \mathrm{mM} \mathrm{NaCl}$ and $0.1 \%$ Tween $20, \mathrm{pH} 7.8$ ) at room temperature. Blocked membranes were washed three times with TBST. The blots were then incubated overnight at $4^{\circ} \mathrm{C}$ with a $1: 1000$ dilution of primary MMP9 antibody (IM09T, Calbiochem, Merck Chemicals Ltd, Nottingham, UK) or a 1:1000 dilution of primary MMP2 antibody (IM83, Calbiochem) in 1\% non-fat dried milk powder in PBST. After three washes with PBST, the blots were incubated for 45 min with horseradish peroxidase-conjugated anti-mouse IgG (sc-2314, Santa Cruz, Heidelberg, Germany) whole antibody at a dilution of 1:10 000 at room temperature, and thereafter washed five times with PBST. Immunoreactive pro- teins were detected by chemiluminescence (ECL detection reagents, RPN2105, Amersham) and exposure to an X-ray film (Hyperfilm, Amersham Biosciences). The intensities of the bands were analysed densitometrically using the NIH Image 1.62 program, and normalized with intensity of bands obtained with monoclonal antibody to GAPDH used as protein loading control. Results are expressed as the mean \pm SEM in arbitrary density unit (ADU).

\section{Statistical analysis}

Differences among groups were determined by ANOVA followed by the Bonferroni's multiple comparison test. Statistical analysis was carried out using GraphPad InStat version 3 (GraphPad Software, San Diego, CA, USA). All differences were considered significant when $P<0.05$.

\section{Materials}

LPS (E. coli 055:B5, ref: L2880) and propranolol were purchased from Sigma-Aldrich, and dissolved in distilled water. SAR150640 was a gift from Sanofi-Midi Research Centre, Exploratory Research Department, Sanofi-Aventis S.p.A. It was dissolved in a mixture of $30 \%$ absolute ethanol, $2 \%$ DMSO and distilled water for the $1 \mathrm{mM}$ solution, and thereafter diluted in distilled water. The final maximal bath concentration was $0.3 \%$ for ethanol and $0.02 \%$ for DMSO.

\section{Results}

LPS stimulation was associated with a time-dependent over-expression of MMP1/MMP2/MMP3/MMP9 transcripts, and an overactivity of MMP9/MMP2

In order to determine the optimal conditions for studying extracellular remodelling in our experimental model, we first performed time-course experiments using stimulation with LPS $\left(10 \mu \mathrm{g} \cdot \mathrm{mL}^{-1}\right)$. Real-time RT-PCR assays showed a timedependent increase in MMP1/MMP2/MMP3/MMP9 transcript levels that reached a maximum at $48 \mathrm{~h}(n=3$ experiments performed with myometrial tissues obtained from three different women) (Figure 1A-D).

Results obtained from two different patients and performed in triplicate showed that MMP9 (Figure 1E) and MMP2 (Figure 1F) activities were increased after 6 and $12 \mathrm{~h}$, respectively, of LPS exposure, and both reached a maximum after $48 \mathrm{~h}$.

Chorioamnionitis was associated with diminution of total collagen and MMP2 and 9 over-expression in human myometrium, mimicked by in vitro stimulation with LPS $\left(10 \mu \mathrm{g} \cdot \mathrm{mL}^{-1}\right)$ for $48 \mathrm{~h}$. 


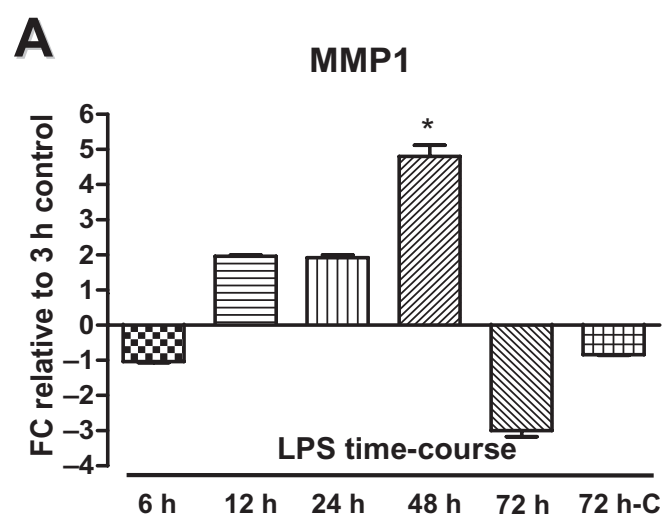

C

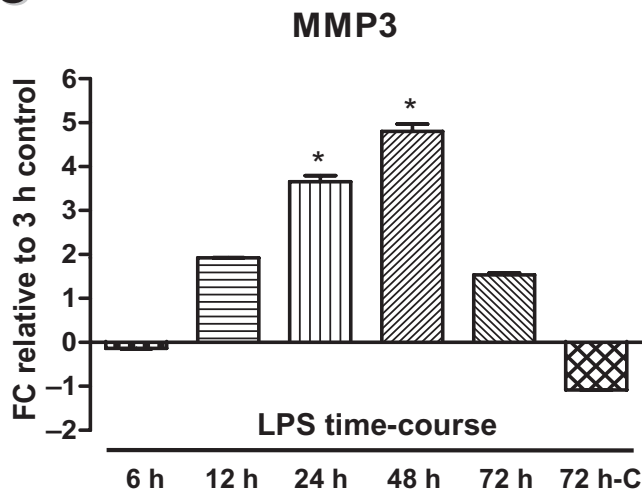

E

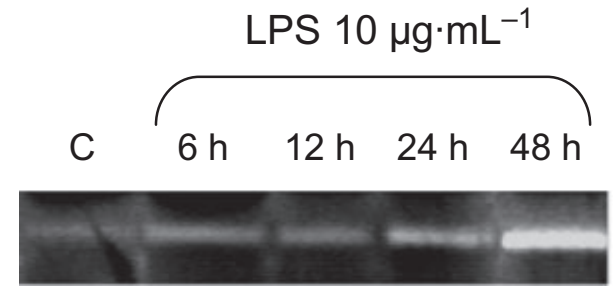

Pro-MMP9

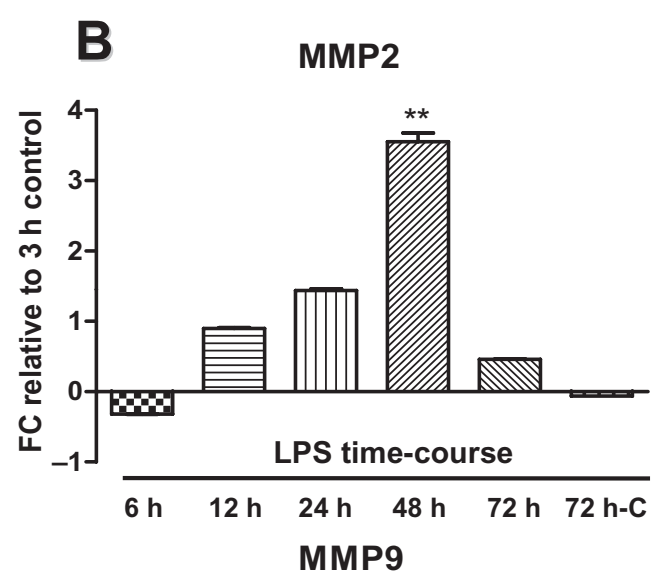

D
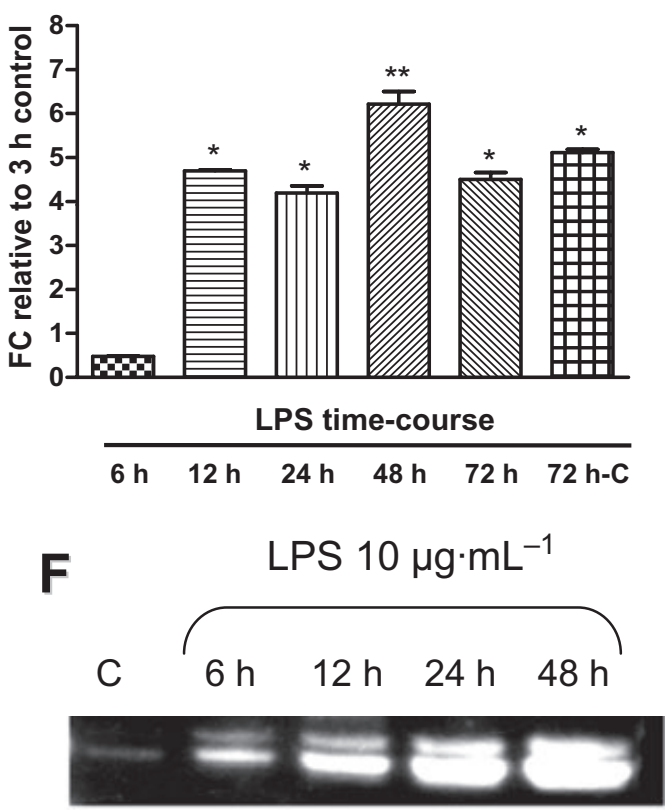

\section{Pro-MMP2}

Figure 1 Time-course of the effect of LPS $\left(10 \mu \mathrm{g} \cdot \mathrm{mL}^{-1}\right)$ on the levels of the transcripts for MMP1, MMP2, MMP3 and MMP9, and on the activities of pro-MMP9 and pro-MMP2. Myometrial explants were incubated with LPS $\left(10 \mu \mathrm{g} \cdot \mathrm{mL}^{-1}\right)$ for $6-72 \mathrm{~h}$. MMP transcripts were assessed using quantitative real-time RT-PCR, and proteolytic activity of pro-MMP-9 and pro-MMP2 secreted into the culture medium was assessed by gelatin zymography. Experiments were performed in triplicate, respectively, on three myometrial samples for RT-PCR and on two supernatants for zymography analysis, each obtained from a different woman. A $72 \mathrm{~h}$ time-matched control without LPS stimulation was performed $(72 \mathrm{~h}-\mathrm{C}) .{ }^{*} P<0.05,{ }^{*} \mathrm{P}<0.01$ versus control $3 \mathrm{~h}$.

Myometrial samples obtained from women with chorioamnionitis $(n=3)$ or elective caesarean delivery were stimulated ( $n=3$; in triplicate) with LPS $\left(10 \mu \mathrm{g} \cdot \mathrm{mL}^{-1}\right)$ for $48 \mathrm{~h}$, in the absence or in the presence of SAR 150640, a $\beta_{3}$-adrenoceptor agonist, at $0.1,1$ and $10 \mu \mathrm{M}$ ( $n=3$ for each group). Control samples were not exposed to LPS. Sections of these samples were stained with Sirius Red, and the results are shown in Figure 2. Compared with control conditions (Figure 2A), LPS stimulation (Figure 2C) and chorioamnionitis (Figure 2B) were both associated with a marked diminution of total collagen $(P<0.001)$, indicating remodelling of the myometrial extracellular matrix. This effect of LPS on collagen expression was antagonized in a concentration-dependent manner by
SAR 150640 (Figure 2D-F for 0.1, 1 and $10 \mu \mathrm{M}$ respectively). Semi-quantification (Figure $2 \mathrm{G}$ ) confirmed that total collagen expression was significantly reduced in case of chorioamnionitis or LPS stimulation, an effect of LPS that was prevented in a concentration-dependent manner by SAR 150640 , although statistical significance was only reached at the highest $(10 \mu \mathrm{M})$ concentration. As suggested by optical analysis of Figure 3, this decrease preferentially involved the large collagen fibres (bright yellow or orange) rather than the thinner or reticular ones (green).

Western blotting of membranes prepared from pregnant myometrium obtained from the same three women with chorioamnionitis (performed in duplicate) or from five 

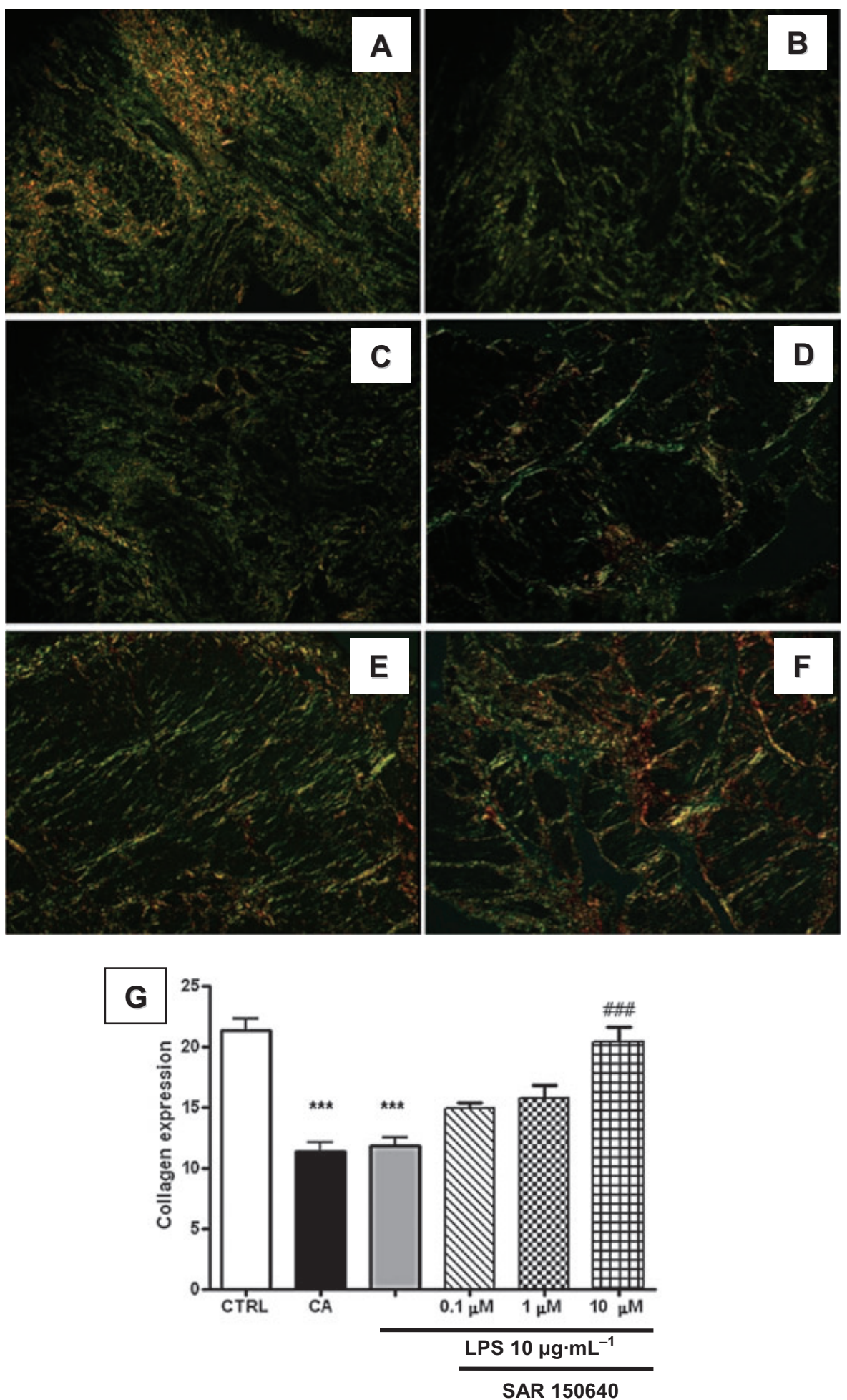

Figure 2 Chorioamnionitis and LPS stimulation $\left(10 \mu \mathrm{g} \cdot \mathrm{mL}^{-1}, 48 \mathrm{~h}\right)$ are associated with diminution of total collagen. Sirius Red staining of human myometrial sections ( $\times 100$ magnification). (A-F) Negative control, chorioamnionitis, LPS stimulation $\left(10 \mu \mathrm{g} \cdot \mathrm{mL}^{-1}, 48 \mathrm{~h}\right)$, without and with SAR 150640 at $0.1,1$ and $10 \mu \mathrm{M}$ respectively. (G) Semi-quantification of total collagen, expressed in $\%$ of fluorescence $\mathrm{mm}^{-2}$. CTRL, control; LPS, $10 \mu \mathrm{g} \cdot \mathrm{mL}^{-1}$ LPS, $48 \mathrm{~h}$; CA, chorioamnionitis. Experiments were performed in myometrial samples obtained from three different women with chorioamnionitis (CA group) and in six myometrial samples obtained from women with uncomplicated pregnancies $(n=3)$ and stimulated with LPS $(n=3)$, without and with SAR 150640 at $0.1,1$ and $10 \mu \mathrm{M}$. ${ }^{* * * P}<0.001$ versus control and \#\#\#P<0.001 versus chorioamnionitis or LPS stimulation. 

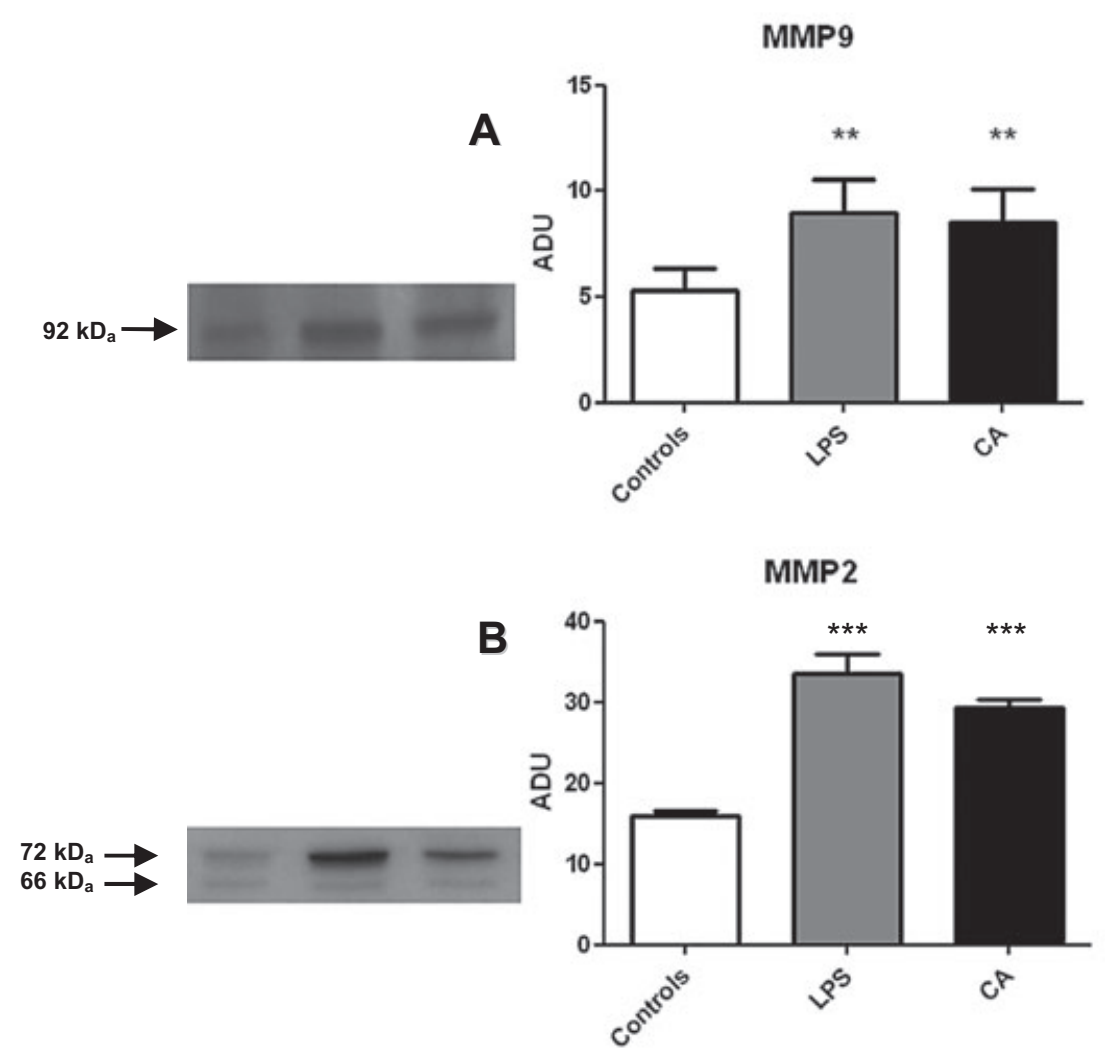

Figure 3 Chorioamnionitis and LPS stimulation $\left(10 \mu \mathrm{g} \cdot \mathrm{mL}^{-1}, 48 \mathrm{~h}\right)$ are associated with MMP9 and MMP2 over-expression. Western blot experiments performed on myometrial samples obtained from women with uncomplicated pregnancies, stimulated or not with LPS, and from women with confirmed chorioamnionitis, showing MMP9 (A) and MMP2 (B) expression. $n=3$ for chorioamionitis and 5 for LPS experiment, which were all performed in duplicate. Controls, control time-matched experiments; LPS, $10 \mu \mathrm{g} \cdot \mathrm{mL}^{-1} \mathrm{LPS} 48 \mathrm{~h}$; CA, chorioamnionitis. $* * P<0.01$ and ${ }^{* * *} P<0.001$ versus controls.

caesarean section and stimulated, or not (controls), with LPS, revealed a $92 \mathrm{kDA}$ band corresponding to MMP9 (Figure 3A) and two 72 and $66 \mathrm{kDa}$ bands corresponding, respectively, to pro-MMP2 and MMP2 (Figure 3B). Densitometric immunoblot analysis indicated that MMP2 (corresponding to the $72 \mathrm{kDa}$ band) and MMP9 protein were significantly over-expressed both in case of chorioamnionitis, and after LPS stimulation, compared with elective caesarean delivery without LPS stimulation used as control (Figure 3A and $\mathrm{B}$ respectively). The over-expression of MMP2 and MMP9 induced by LPS stimulation was to the same extent as that observed in membranes prepared from pregnant myometrium with chorioamnionitis (Figure 3A,B), providing external validation of the in vitro model of chorioamnionitis induced by LPS.

Effect of SAR150640, a selective $\beta_{3}$-adrenoceptor agonist, on LPS-induced MMP9 activity and expression

Gelatin zymography experiments $(n=4)$ with supernatants from pregnant myometrium stimulated with LPS $\left(10 \mu \mathrm{g} \cdot \mathrm{mL}^{-1}\right.$, $48 \mathrm{~h}$ ) revealed that LPS increased the proteolytic activity of pro-MMP9 and that was antagonized by the selective $\beta_{3}$-adrenoceptor agonist, SAR150640 (Figure 4A,B). This effect appeared to be maximal at the lowest concentration of SAR150640 tested $(0.1 \mu \mathrm{M}$; Figure 4B), and was, at least partially, explained by a decrease in protein expression, as
LPS-induced over-expression of MMP9 protein, observed in Western blot analysis (Figure 4C), was also prevented by the $\beta_{3}$-adrenoceptor agonist. Again, the effect of SAR150640 was maximal at the lowest concentration used in the present study $(0.1 \mu \mathrm{M}$; Figure $4 \mathrm{D})$. SAR150640 had no effect by itself on MMP9 activity or expression in myometrial samples not stimulated with LPS (data not shown).

Effect of SAR150640 on LPS-induced MMP2 activity and expression

Gelatin zymography experiments $(n=4)$ prepared from pregnant myometrium stimulated with LPS $\left(10 \mu \mathrm{g} \cdot \mathrm{mL}^{-1}, 48 \mathrm{~h}\right)$ revealed that LPS induced a significant increase in proteolytic activity of pro-MMP2 that was antagonized by the selective $\beta_{3}$-adrenoceptor agonist, SAR150640 (Figure 5A,B).

This effect of SAR150640 on proteolytic activity of MMP2 was at least partially explained by a decrease in protein expression as the LPS-induced MMP2 protein over-expression by Western blot analysis ( $n=6$; Figure 5 C) was prevented by treatment with the $\beta_{3}$-adrenoceptor agonist, in a concentration-dependent manner (Figure 5C,D). This effect was statistically significant from the lowest concentration of SAR150640 $(0.1 \mu \mathrm{M}, P<0.05)$. As found with MMP9, SAR150640 had no effect by itself on unstimulated (no LPS) MMP2 activity or expression (data not shown). 
A

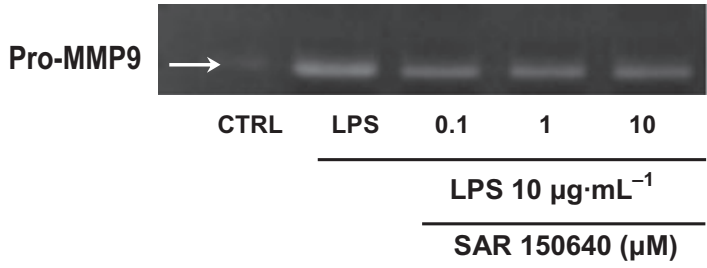

C

MMP-9

GAPDH

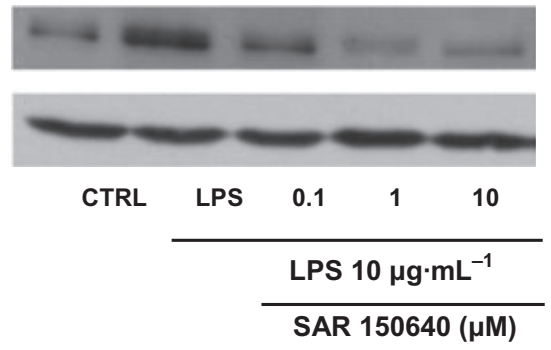

B

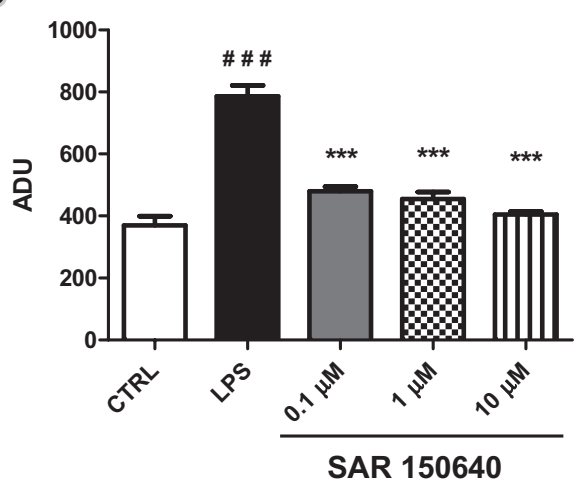

D

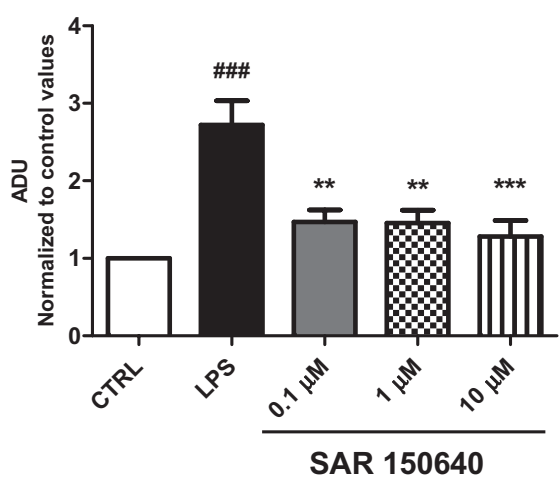

Figure 4 SAR150640 prevents LPS-induced MMP9 activity and expression. Gelatin zymography analysis (A) with semi-quantification of pro-MMP9 activity (B) and Western blot analysis (C) with semi-quantification (D) showing the expression of MMP9 protein. Legends: CTRL, control time-matched experiments; LPS, $10 \mu \mathrm{g} \cdot \mathrm{mL}^{-1}$ LPS $48 \mathrm{~h}$; SAR150640 $(0.1,1,10 \mu \mathrm{M})$ was added 20 min prior to LPS stimulation. Experiments were performed, respectively, on four and seven myometrial samples for zymography and Western blot analysis, each obtained from a different woman. \#\#\#P<0.001 versus controls, ${ }^{* * *} P<0.001$ versus LPS.

Effects of propranolol on the modulation of LPS-induced MMP9 expression by SAR150640

In the last set of experiments, we assessed the specificity of the effect observed with SAR150640. We used propranolol, a nonselective $\beta$-adrenoceptor antagonist, which blocks $\beta_{1^{-}}$and $\beta_{2}$-adrenoceptors at $0.1 \mu \mathrm{M}$ and blocks all subtypes of $\beta$-adrenoceptors at a higher concentration $(10 \mu \mathrm{M}$; Roberts et al., 1995; Hoffmann et al., 2004).

The effect of SAR150640 on MMP9 protein production was not modified after pretreatment of the myometrial samples with propranolol $(0.1 \mu \mathrm{M})$, whereas it was abolished by the higher concentration of propranolol $(10 \mu \mathrm{M})$ (Figure 6). Furthermore, propranolol $(0.1$ and $10 \mu \mathrm{M})$ had no effect by itself on MMP9 expression in tissues stimulated with LPS (in ADU $2.21 \pm 0.3,2.27 \pm 0.24,2.17 \pm 0.23$, respectively, for LPS, LPS with $0.1 \mu \mathrm{M}$ propranolol and LPS with $10 \mu \mathrm{M}$ propranolol groups, ANOVA $P<0.05$ ). These experiments were carried out with six myometrial samples obtained from six different women.

\section{Discussion}

Inflammation, induced by infection in the case of chorioamnionitis, plays a well-established role in the aetiology of preterm labour, with evidence that it simultaneously exerts an adverse effect on the developing fetal or neonatal brain, with resultant negative implications for development in later childhood. Furthermore, there is clear evidence of a link between genital tract infection and preterm labour, although infections are frequently difficult to detect.

Our data demonstrate for the first time that chorioamnionitis is associated with remodelling of the human myometrial extracellular matrix, explained, at least partly, by an overexpression of MMP2 and MMP9. Optical analysis of Sirius Red staining of sections of myometrial samples obtained from women with chorioamnionitis, or after LPS stimulation (Figure 3), suggests that diminution of collagen involves more of the larger, than of the thinner or reticular, fibres, as shown by the more pronounced diminution of bright yellow-orange fibres, a mechanism that might lead to a gain of elasticity, necessary for preparing the uterus for the synchronized contractions of labour (Shynlova et al., 2004). These findings are in keeping with a recently published study, conducted in pregnant ewes, albeit in a different tissue system, which indicated that MMP2 expression was increased both after betamethasone treatment or intra-amniotic injection of $10 \mathrm{mg}$ endotoxin, suggesting that MMP2-induced remodelling of lung structure might be involved in the maturation of fetal lung (Sweet et al., 2008). 


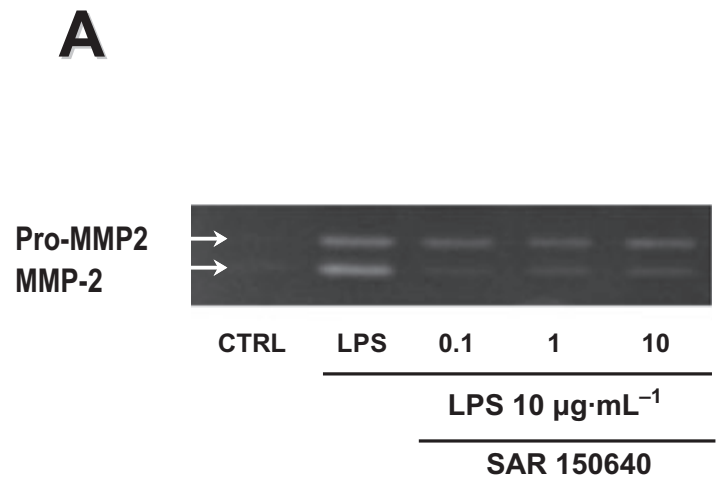

MMP-2

GAPDH

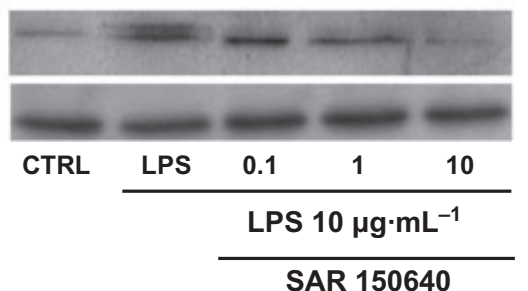

B

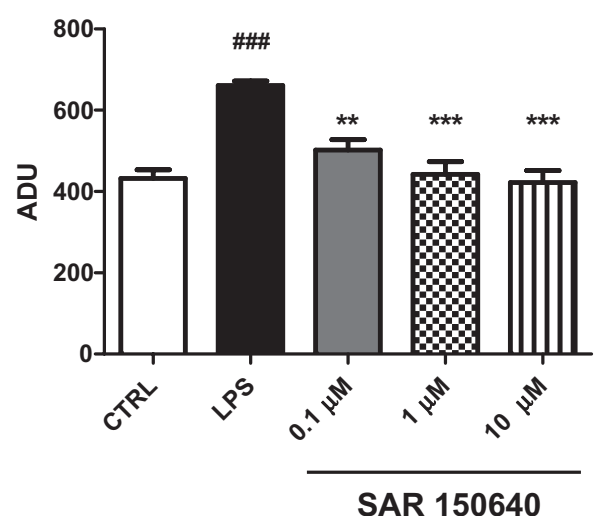

D

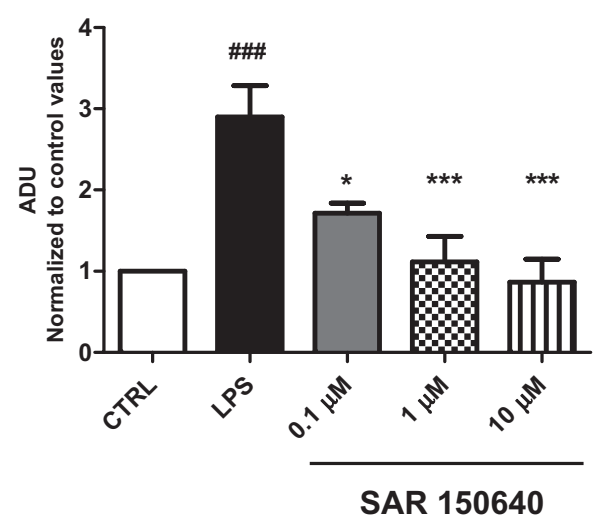

Figure 5 SAR150640 prevents LPS-induced MMP2 activity and expression. Gelatin zymography analysis (A) with semi-quantification of pro-MMP2/MMP2 activity (B) and Western blot analysis (C) with semi-quantification (D) showing the expression of MMP2 protein. Legends: CTRL, control time-matched experiments; LPS, $10 \mu \mathrm{g} \cdot \mathrm{mL}^{-1}$ LPS $48 \mathrm{~h}$; SAR150640 $(0.1,1,10 \mu \mathrm{M})$ was added 20 min prior to LPS stimulation. Experiments were performed, respectively, on four and six myometrial samples for zymography and Western blot analysis, each obtained from a different woman. \#\#\#P<0.001 versus controls; ${ }^{*} P<0.05$, ${ }^{* *} P<0.01$ and ${ }^{* * *} P<0.0001$ versus LPS.

Whereas the relationship between infection and myometrial remodelling is a new finding in human near-term myometrium, it has already been reported that labour is associated with uterine remodelling. Indeed, Shynlova et al., (2004) have shown that a decrease in expression of fibrillar collagens and a coordinated temporal increase in expression of components of the basement membrane occurred in the human myometrium near term our findings expand on those of $\mathrm{O}^{\prime}$ Brien et al., (2007), who have shown in human myometrial cells that labour is associated with an up-regulation of MMP3 and a down-regulation of $\alpha 5$ integrin (ITGA5), a divalent cationdependent heterodimeric, transmembrane receptor that mediates cell attachment to the extracellular matrix and signal transduction from the extracellular matrix to the cell. These results suggest that increased activity or expression of different MMPs in human myometrium would be required for the uterine tissue remodelling, taking place during labour and in the post-partum period.

We have shown that our model of LPS-induced inflammation, in myometrial samples from normal pregnant women, was associated with the same decrease of total collagen, and of MMP9 and MMP2 over-expression, as that observed in myometrial samples from patients with chorioamnionitis, providing validation of this in vitro model. We also observed that
LPS-induced remodelling is associated with an overactivity of MMP9 and MMP2, which are two major gelatinases, that preferentially digest type I and III collagen (Visse and Nagase, 2003), two major components of myometrial extracellular matrix (Schwalm and Dubrauszky, 1966; Fata et al., 2000). These results are in good agreement with those of Roh et al. (2000) who have shown that the gelatinolytic activity of proMMP-9, in human myometrial smooth muscle cells, is dramatically increased during labour. This increase in proMMP-9 activity is under control of IL1 and tumour necrosis factor, which are two pro-inflammatory cytokines well known to play a role in the initiation of labour (Romero et al., 2006), by activating the transcription factor NFKB1 (Lindstrom and Bennett, 2005). NFKB1 activity increases with labour onset and is central to multiple pro-labour pathways, such as prostaglandin synthesis, MMP expression and proinflammatory cytokines (Lindstrom and Bennett, 2005).

Our findings support the concept that parturition is associated with an elevated concentration of MMPs in different tissues, including vagina (Wieslander et al., 2008), myometrium (Roh et al., 2000), amniotic fluid (Park et al., 2003) and maternal blood, from different species, even if the tissue site or organ which primarily regulates this elevation is not clearly defined. Up to now, little is known about the 


\section{B $\quad$ MMP9}

MMP-9
GAPDH
\begin{tabular}{|l|c|c|c|c|c|}
\hline Solvent & + & & & & \\
\hline LPS $\left(10 \mu \mathrm{g} \cdot \mathrm{mL}^{-1}\right)$ & - & + & + & + & + \\
\hline SR150640 $(\mu \mathrm{M})$ & - & - & 1 & 1 & 1 \\
\hline Propranolol $(\mu \mathrm{M})$ & - & - & - & 0.1 & 10 \\
\hline
\end{tabular}

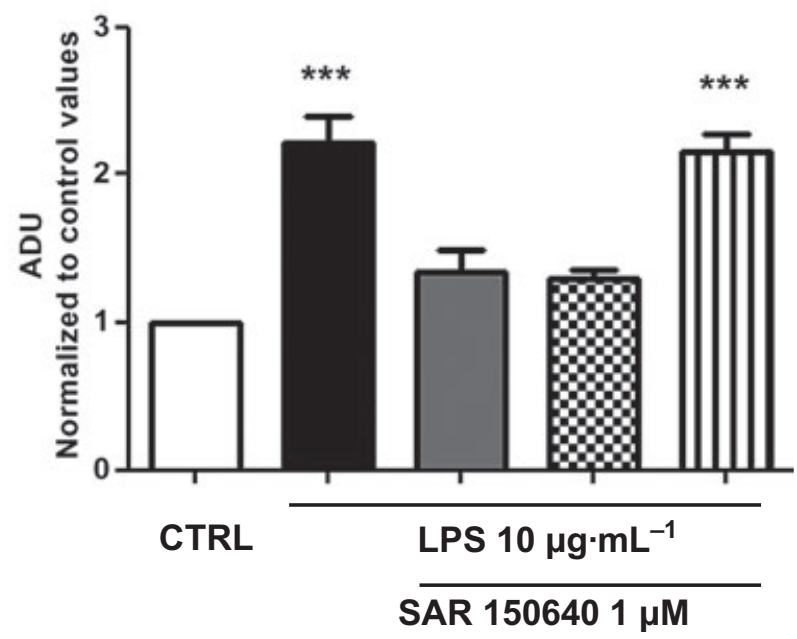

$\overline{\text { Propranolol }}$

$0.1 \mu \mathrm{M} \quad 10 \mu \mathrm{M}$

Figure 6 The effect of SAR150640 on LPS-induced MMP9 expression is mediated only by $\beta_{3}$-adrenoceptors. Western blot analysis (A) with semi-quantification (B) showing the expression of MMP9 protein. Controls, time-matched experiments; LPS, $10 \mu \mathrm{g} \cdot \mathrm{mL}^{-1} \mathrm{LPS} 48 \mathrm{~h}$. SAR150640 $(0.1,1,10 \mu \mathrm{M})$ was added 20 min prior to LPS stimulation. Experiments were performed on six myometrial samples, each obtained from a different woman. ${ }^{* * *} P<0.001$ versus controls.

production and regulation of MMP in human myometrium in relation to parturition, and the present study is the first report of MMP2 expression and physiological role in myometrium, although its expression has been documented in decidual stromal cells (Zhu et al., 2009), cervix (Simon and Einspanier, 2009) or endometrium (Labied et al., 2009).

Nevertheless, there is strong evidence to suggest that MMP may be involved in different mechanisms of normal and preterm labour (Roh et al., 2000; Maymon et al., 2001). For example, Maymon et al., (2001) have shown that human parturition and rupture of fetal membranes, both term and preterm, are associated with a significant decrease in amniotic fluid concentrations of tissue inhibitor of MMP-2. Furthermore, labour was associated with an over-expression of MMP9 and MMP2 in fetal membranes, facilitating their rupture (Yonemoto et al., 2006), and increases in MMP9 and MMP2 were involved in cervical ripening (Stygar et al., 2002).

The second key finding of this work is that the selective $\beta_{3}$-adrenoceptor agonist, SAR150640, was able to oppose LPSinduced remodelling, by decreasing MMP9 and MMP2 activity and protein expression in a concentration-dependent manner, a strong argument in favour of a pharmacologically mediated effect. The effect on MMP activities was statistically significant at $0.1 \mu \mathrm{M}$, which is the lowest concentration of SAR150640 used, indicating that SAR150640 exhibits a good potency. This is of particular interest as work from our group has suggested the potential application of $\beta_{3}$-adrenoceptor agonists in the pharmacological management of preterm labour (Bardou et al., 2000; Dennedy et al., 2002; Rouget et al., 2004; 2005; Croci et al., 2007; Lirussi et al., 2008). However, our findings seem to contradict many other reports, suggest- ing that $\beta$-adrenoceptor stimulation, as would result from chronic catecholamine exposure, is more commonly associated with an activation of MMP and an increase in remodelling involved in the development of cardiac failure, giving a rationale for the use of $\beta$-adrenoceptor antagonists ( $\beta$-blockers) in heart failure (Sabbah, 2004).

Up to now, there are no data pertaining to a direct relationship between $\beta_{3}$-adrenoceptor agonists and remodelling or MMP activity. Nevertheless, Steinle et al., (2005) showed that $\beta_{3}$-adrenoceptor stimulation was associated with an increase in choroidal endothelial cell invasion and proliferation. The invasion response was inhibited by an inhibitor of MMP $2 / 9$ (MMP-I), suggesting that invasion triggered by $\beta_{3}$-adrenoceptor stimulation depends upon MMP9 and MMP2. However, the authors did not demonstrate a direct link between $\beta_{3}$-adrenoceptor stimulation, MMP activation and the invasion process.

In this work, we did not study the pathway(s) activated by $\beta_{3}$-adrenoceptor stimulation, which prevents up-regulation of MMPs. However, we can suggest, or speculate, that the previously reported cAMP increase in myometrium induced by $\beta_{3}$-adrenoceptor stimulation (Bardou et al., 2000; Rouget et al., 2004), is implicated in the observed decrease in MMP9 and MMP2. Indeed, different studies have confirmed the role of cAMP in controlling MMP activities and expression, and subsequently remodelling. For instance, Martin-Chouly et al., (2004) have demonstrated that cAMP modulated MMP production from human lung fibroblasts. Furthermore, Oger et al., (2005) have shown that rolipram, a PDE4 inhibitor, was able to prevent MMP9 overactivity in human amniochorionic membranes, stimulated with LPS. 
Finally, we confirmed the specificity of the effect of SAR150640 on MMP expression with propranolol, which is a non-selective $\beta$-adrenoceptor antagonist, as there are still no specific antagonists of $\beta_{3}$-adrenoceptors available. We demonstrated that, with an intermediate concentration $(1 \mu \mathrm{m})$, SAR150640 selectively stimulates the $\beta_{3}$-adrenoceptor system. These results are consistent with those of Croci et al. (2007) where the selectivity of this agonist has been tested on a hundred in vitro models.

One of the limitations of our work is that most of the experiments were performed on myometrial samples obtained from women at or near term, as that is the closest possible model that is practically attainable. There is no real evidence to suggest that the mechanisms of myometrial regulation, and the functional aspects of myometrial contractility, differ from early to late periods of gestation, in the same clinical situations. Furthermore, according to already published data on the topic, including some showing that MMP9 was increased in the maternal serum of women delivering preterm, compared to those delivering at term (Poon et al., 2009), our findings provide valuable clues for a better understanding of infection/inflammation-triggered labour.

Another minor limitation of our study is that because no bacteriological or histological assessment of placenta was performed in case of uncomplicated pregnancy, we cannot formally rule out the presence of bacteria that have been shown to be present even in fetal membranes of normal-term pregnancies, by sensitive approaches such as fluorescence in situ hybridization (Steel et al., 2005). Nevertheless, the clinical meaning of this finding remains controversial, and we have shown that myometrial samples obtained from what is called normal pregnancies by our obstetricians did not exhibit the same patterns of myometrial changes as those observed in cases of chorioamnionitis (see also our previous work on the same model, Lirussi et al., 2008).

To summarize, we have demonstrated that: (i) chorioamnionitis was associated with remodelling of human myometrium, and MMP9 and 2 over-expression; (ii) under experimental conditions reproducing chorioamnionitis, LPSinduced remodelling was associated with an over-expression and overactivity of MMP9 and MMP2; (iii) SAR150640, a new $\beta_{3}$-adrenoceptor agonist, was able to prevent myometrial remodelling induced by LPS stimulation; and (iv) that the effect observed was specific to the $\beta_{3}$-adrenoceptor subtype. Taken together, these results provide a better understanding of the myometrial consequences of human chorioamnionitis. In light of our previous reports, the present study emphasizes the potential value of the $\beta_{3}$-adrenoceptor agonist, SAR150640, in the pharmacological management of preterm labour, as it is able to oppose both the triggering mechanisms, that is remodelling, inflammation, apoptosis and their consequences (i.e. myometrial contractions).

\section{Acknowledgements}

This work was supported by a grant from the Conseil Régional de Bourgogne and the Centre Hospitalier Universitaire (CHU) de Dijon, France.

The authors wish to express their gratitude to the Obstetrics \& Gynecology Departments of the Hôpital du Bocage, Dijon
(France) for making tissue samples available to us. We also wish to thank Agnes Maurer, project manager at the Clinical Research Head Quarter of the CHU de Dijon, for all technical and administrative aspects of this study.

\section{Conflicts of interest}

M.B. is affiliated to the French Drug Agency (Agence Française de Sécurité Sanitaire des Produits de Santé), and is a member of the Transparency Committee at the Haute Autorité de Santé. His conflicts of interest are available on both websites (http://www.has-sante.fr and http://www.afssaps.fr).

\section{References}

Alexander SPH, Mathie A, Peters JA (2008). Guide to Receptors and Channels (GRAC), 3rd edn. Br J Pharmacol 153 (Suppl. 2): S1-S209.

Ananth CV, Misra DP, Demissie K, Smulian JC (2001). Rates of preterm delivery among black women and white women in the United States over two decades: an age-period-cohort analysis. Am J Epidemiol 154: 657-665.

Bardou M, Loustalot C, Cortijo J, Simon B, Naline E, Dumas M et al. (2000). Functional, biochemical and molecular biological evidence for a possible beta(3)-adrenoceptor in human near-term myometrium. Br J Pharmacol 130: 1960-1966.

Borges LF, Gutierrez PS, Marana HR, Taboga SR (2007). Picrosiriuspolarization staining method as an efficient histopathological tool for collagenolysis detection in vesical prolapse lesions. Micron 38: 580-583.

Christiaens I, Zaragoza DB, Guilbert L, Robertson SA, Mitchell BF, Olson DM (2008). Inflammatory processes in preterm and term parturition. J Reprod Immunol 79: 50-57.

Croci T, Cecchi R, Marini P, Rouget C, Viviani N, Germain G et al. (2007). In vitro and in vivo pharmacological characterization of ethyl-4-[trans-4-[((2S)-2-hydroxy-3-[4-hydroxy-

3 [(methylsulfonyl)amino]-ph enoxy]propyl) amino]cyclohexyl]benzoate hydrochloride (SAR150640), a new potent and selective human beta3-adrenoceptor agonist for the treatment of preterm labor. J Pharmacol Exp Ther 321: 1118-1126.

Dennedy MC, Houlihan DD, McMillan H, Morrison JJ (2002). Beta2and beta3-adrenoreceptor agonists: human myometrial selectivity and effects on umbilical artery tone. Am J Obstet Gynecol 187: 641-647.

Edwards RK (2005). Chorioamnionitis and labor. Obstet Gynecol Clin North Am 32: 287-296.

Ekelund CK, Vogel I, Skogstrand K, Thorsen P, Hougaard DM, Langhoff-Roos J et al. (2008). Interleukin-18 and interleukin-12 in maternal serum and spontaneous preterm delivery. I Reprod Immunol 77: 179-185.

Fata JE, Ho AT, Leco KJ, Moorehead RA, Khokha R (2000). Cellular turnover and extracellular matrix remodeling in female reproductive tissues: functions of metalloproteinases and their inhibitors. Cell Mol Life Sci 57: 77-95.

Fortunato SJ, Menon R, Swan KF, Lyden TW (1994). Organ culture of amniochorionic membrane in vitro. Am J Reprod Immunol 32: 184187.

Goldenberg RL, Rouse DJ (1998). Prevention of premature birth. N Engl J Med 339: 313-320.

Goldenberg RL, Culhane JF, Iams JD, Romero R (2008). Epidemiology and causes of preterm birth. Lancet 371: 75-84.

Hoffmann C, Leitz MR, Oberdorf-Maass S, Lohse MJ, Klotz KN (2004). Comparative pharmacology of human beta-adrenergic receptor 
subtypes - characterization of stably transfected receptors in $\mathrm{CHO}$ cells. Naunyn Schmiedebergs Arch Pharmacol 369: 151-159.

Junqueira LC, Bignolas G, Brentani RR (1979). Picrosirius staining plus polarization microscopy, a specific method for collagen detection in tissue sections. Histochem J 11: 447-455.

Labied S, Galant C, Nisolle M, Ravet S, Munaut C, Marbaix E et al. (2009). Differential elevation of matrix metalloproteinase expression in women exposed to levonorgestrel-releasing intrauterine system for a short or prolonged period of time. Hum Reprod 24: 113-121.

Larroque B, Ancel PY, Marret S, Marchand L, Andre M, Arnaud C et al. (2008). Neurodevelopmental disabilities and special care of 5-yearold children born before 33 weeks of gestation (the EPIPAGE study): a longitudinal cohort study. Lancet 371: 813-820.

Leroy MJ, Cedrin I, Breuiller M, Giovagrandi Y, Ferre F (1989). Correlation between selective inhibition of the cyclic nucleotide phosphodiesterases and the contractile activity in human pregnant myometrium near term. Biochem Pharmacol 38: 9-15.

Lindstrom TM, Bennett PR (2005). The role of nuclear factor kappa B in human labour. Reproduction 130: 569-581.

Lirussi F, Rakotoniaina Z, Madani S, Goirand F, Breuiller-Fouche M, Leroy MJ et al. (2008). ADRB3 adrenergic receptor is a key regulator of human myometrial apoptosis and inflammation during chorioamnionitis. Biol Reprod 78: 497-505.

Manase K, Endo T, Chida M, Nagasawa K, Honnma H, Yamazaki K et al. (2006). Coordinated elevation of membrane type 1-matrix metalloproteinase and matrix metalloproteinase-2 expression in rat uterus during postpartum involution. Reprod Biol Endocrinol 4: 32.

Martin JA, Hamilton BE, Sutton PD, Ventura SJ, Menacker F, Kirmeyer S (2006). Births: final data for 2004. Natl Vital Stat Rep 55: 1-101.

Martin-Chouly CA, Astier A, Jacob C, Pruniaux MP, Bertrand C, Lagente V (2004). Modulation of matrix metalloproteinase production from human lung fibroblasts by type 4 phosphodiesterase inhibitors. Life Sci 75: 823-840.

Maymon E, Romero R, Pacora P, Gomez R, Mazor M, Edwin S et al. (2001). A role for the $72 \mathrm{kDa}$ gelatinase (MMP-2) and its inhibitor (TIMP-2) in human parturition, premature rupture of membranes and intraamniotic infection. J Perinat Med 29: 308-316.

Monga M, Sanborn BM (1995). Uterine contractile activity. Introduction. Semin Perinatol 19: 1-2.

O'Brien M, O'Shaughnessy D, Ahamide E, Morrison JJ, Smith TJ (2007). Differential expression of the metalloproteinase MMP3 and the \{alpha\} 5 integrin subunit in human myometrium at labour. Mol Hum Reprod 13: 655-661.

Oger S, Mehats C, Dallot E, Cabrol D, Leroy MJ (2005). Evidence for a role of phosphodiesterase 4 in lipopolysaccharide-stimulated prostaglandin E2 production and matrix metalloproteinase-9 activity in human amniochorionic membranes. J Immunol 174: 8082-8289.

Oner C, Schatz F, Kizilay G, Murk W, Buchwalder LF, Kayisli UA et al. (2008). Progestin-inflammatory cytokine interactions affect matrix metalloproteinase- 1 and -3 expression in term decidual cells: implications for treatment of chorioamnionitis-induced preterm delivery. J Clin Endocrinol Metab 93: 252-259.

Park KH, Chaiworapongsa T, Kim YM, Espinoza J, Yoshimatsu J, Edwin $S$ et al. (2003). Matrix metalloproteinase 3 in parturition, premature rupture of the membranes, and microbial invasion of the amniotic cavity. J Perinat Med 31: 12-22.

Poon LC, Nekrasova E, Anastassopoulos P, Livanos P, Nicolaides KH (2009). First-trimester maternal serum matrix metalloproteinase-9 (MMP-9) and adverse pregnancy outcome. Prenat Diagn 29: 553559.

Redline RW, Faye-Petersen O, Heller D, Qureshi F, Savell V, Vogler C (2003). Amniotic infection syndrome: nosology and reproducibility of placental reaction patterns. Pediatr Dev Pathol 6: 435-448.

Redline RW, Heller D, Keating S, Kingdom J (2005). Placental diagnostic criteria and clinical correlation - a workshop report. Placenta 26 (Suppl. A): S114-S117.
Roberts SJ, Russell FD, Molenaar P, Summers RJ (1995). Characterization and localization of atypical beta-adrenoceptors in rat ileum. $\mathrm{Br}$ J Pharmacol 116: 2549-2556.

Roh CR, Oh WJ, Yoon BK, Lee JH (2000). Up-regulation of matrix metalloproteinase-9 in human myometrium during labour: a cytokine-mediated process in uterine smooth muscle cells. Mol Hum Reprod 6: 96-102.

Romero R, Espinoza J, Goncalves LF, Kusanovic JP, Friel LA, Nien JK (2006). Inflammation in preterm and term labour and delivery. Semin Fetal Neonatal Med 11: 317-326.

Romero R, Espinoza J, Goncalves LF, Kusanovic JP, Friel L, Hassan S (2007). The role of inflammation and infection in preterm birth. Semin Reprod Med 25: 21-39.

Rouget C, Breuiller-Fouche M, Mercier FJ, Leroy MJ, Loustalot C, Naline E et al. (2004). The human near-term myometrial beta3adrenoceptor but not the beta2-adrenoceptor is resistant to desensitisation after sustained agonist stimulation. Br J Pharmacol 141: 831-841.

Rouget C, Bardou M, Breuiller-Fouche M, Loustalot C, Qi H, Naline E et al. (2005). Beta3-adrenoceptor is the predominant betaadrenoceptor subtype in human myometrium and its expression is up-regulated in pregnancy. J Clin Endocrinol Metab 90: 1644-1650.

Sabbah HN (2004). Biologic rationale for the use of beta-blockers in the treatment of heart failure. Heart Fail Rev 9: 91-97.

Schwalm H, Dubrauszky V (1966). The structure of the musculature of the human uterus - muscles and connective tissue. Am J Obstet Gynecol 94: 391-404.

Shimizu K, Maekawa K (1983). Collagen degradation in the mouse uterus during postpartum involution: extracellular pathway. Acta Anat (Basel) 117: 257-260.

Shynlova O, Mitchell JA, Tsampalieros A, Langille BL, Lye SJ (2004). Progesterone and gravidity differentially regulate expression of extracellular matrix components in the pregnant rat myometrium. Biol Reprod 70: 986-992.

Simon C, Einspanier A (2009). The hormonal induction of cervical remodeling in the common marmoset monkey (Callithrix jacchus). Reproduction 137: 517-525.

Smith R (2007). Parturition. N Engl J Med 356: 271-283.

Steel JH, Malatos S, Kennea N, Edwards AD, Miles L, Duggan P et al. (2005). Bacteria and inflammatory cells in fetal membranes do not always cause preterm labor. Pediatr Res 57: 404-411.

Steinle JJ, Zamora DO, Rosenbaum JT, Granger HJ (2005). Beta 3 -adrenergic receptors mediate choroidal endothelial cell invasion, proliferation, and cell elongation. Exp Eye Res 80: 83-91.

Stygar D, Wang H, Vladic YS, Ekman G, Eriksson H, Sahlin L (2002). Increased level of matrix metalloproteinases 2 and 9 in the ripening process of the human cervix. Biol Reprod 67: 889-894.

Sweet DG, Huggett MT, Warner JA, Moss TJ, Kloosterboer N, Halliday HL et al. (2008). Maternal betamethasone and chorioamnionitis induce different collagenases during lung maturation in fetal sheep. Neonatology 94: 79-86.

Vadillo-Ortega F, Estrada-Gutierrez G (2005). Role of matrix metalloproteinases in preterm labour. BJOG 112 (Suppl. 1): 19-22.

Visse R, Nagase H (2003). Matrix metalloproteinases and tissue inhibitors of metalloproteinases: structure, function, and biochemistry. Circ Res 92: 827-839.

Weiss A, Goldman S, Shalev E (2007). The matrix metalloproteinases (MMPS) in the decidua and fetal membranes. Front Biosci 12: 649659

Wieslander CK, Marinis SI, Drewes PG, Keller PW, Acevedo JF, Word RA (2008). Regulation of elastolytic proteases in the mouse vagina during pregnancy, parturition, and puerperium. Biol Reprod 78: 521-528.

Yonemoto H, Young CB, Ross JT, Guilbert LL, Fairclough RJ, Olson DM (2006). Changes in matrix metalloproteinase (MMP)-2 and MMP-9 in the fetal amnion and chorion during gestation and at term and preterm labor. Placenta 27: 669-677. 
Zhang H, Sun L, Wang W Ma X (2006). Quantitative analysis of fibrosis formation on the microcapsule surface with the use of picro-sirius red staining, polarized light microscopy, and digital image analysis. J Biomed Mater Res A 76: 120-125.
Zhu XM, Han T, Sargent IL, Wang YL, Yao YQ (2009). Conditioned medium from human decidual stromal cells has a concentrationdependent effect on trophoblast cell invasion. Placenta 30: 7478. 